\title{
(9) Comparison of CT versus MRI measurements of transverse atlantal ligament integrity in craniovertebral junction injuries. Part 1: A clinical study
}

\author{
Luis Perez-Orribo, MD, PhD, ${ }^{1}$ Laura A. Snyder, MD, ${ }^{2}$ Samuel Kalb, MD, ${ }^{2}$ Ali M. Elhadi, MD, ${ }^{2}$ \\ Forrest Hsu, MD, ${ }^{2}$ Anna G. U. S. Newcomb, MS, ${ }^{1}$ Devika Malhotra, BA, ${ }^{1}$ Neil R. Crawford, PhD, ${ }^{1}$ and \\ Nicholas Theodore, MD²
}

${ }^{1}$ Spinal Biomechanics Laboratory and 'Department of Neurosurgery, Barrow Neurological Institute, St. Joseph's Hospital and Medical Center, Phoenix, Arizona

\begin{abstract}
OBJECTIVE Craniovertebral junction (CVJ) injuries complicated by transverse atlantal ligament (TAL) disruption often require surgical stabilization. Measurements based on the atlantodental interval (ADI), atlas lateral diameter (ALD1), and axis lateral diameter (ALD2) may help clinicians identify TAL disruption. This study used CT scanning to evaluate the reliability of these measurements and other variants in the clinical setting.

METHODS Patients with CVJ injuries treated at the authors' institution between 2004 and 2011 were evaluated retrospectively for demographics, mechanism and location of CVJ injury, classification of injury, treatment, and modified Japanese Orthopaedic Association score at the time of injury and follow-up. The integrity of the TAL was evaluated using MRI. The ADI, ALD1, and ALD2 were measured on CT to identify TAL disruption indirectly.
\end{abstract}

RESULTS Among the 125 patients identified, 40 (32\%) had atlas fractures, 59 (47.2\%) odontoid fractures, $31(24.8 \%)$ axis fractures, and 4 (3.2\%) occipital condyle fractures. TAL disruption was documented on MRI in 11 cases (8.8\%). The average ADI for TAL injury was $1.8 \mathrm{~mm}$ (range $0.9-3.9 \mathrm{~mm}$ ). Nine (81.8\%) of the 11 patients with TAL injury had an ADI of less than $3 \mathrm{~mm}$. In 10 patients (90.9\%) with TAL injury, overhang of the C-1 lateral masses on C-2 was less than 7 $\mathrm{mm}$. ADI, ALD1, ALD2, ALD1 - ALD2, and ALD1/ALD2 did not correlate with the integrity of the TAL.

CONCLUSIONS No current measurement method using CT, including the ADI, ALD1, and ALD2 or their differences or ratios, consistently indicates the integrity of the TAL. A more reliable CT-based criterion is needed to diagnose TAL disruption when MRI is unavailable.

http://thejns.org/doi/abs/10.3171/2015.9.SPINE13808

KEY WORDS transverse atlantal ligament; atlas fracture; measurement; axis fracture; atlantodental interval; atlantoaxial overhang; cervical

$\mathrm{C}$ ERVICAL injuries are present in $2.4 \%$ of patients who experience blunt trauma. ${ }^{11} \mathrm{C}-1$ fractures represent $1.3 \%-2 \%$ of all spinal injuries, $3 \%-13 \%$ of cervical spine injuries, and $25 \%$ of all craniocervical injuries. ${ }^{7,9,10,18}$ When referring to craniocervical injuries, we include injuries affecting the occipital condyle, C-1 ring (Fig. 1), and dens and body of C-2. Treatment of these lesions often requires stabilization with a halo vest orthosis or surgical fixation and fusion.
When deciding whether a patient requires surgical stabilization, neurosurgeons often assess stability of the transverse atlantal ligament (TAL). The TAL maintains the odontoid process of $\mathrm{C}-2$ close to the $\mathrm{C}-1$ ring, allowing rotational movement. Multiple other ligaments, including the capsular ligaments, alar ligaments, apical ligament, anterior longitudinal ligament, and tectorial membrane, assist the TAL in providing cervical stability, but the TAL plays the most important role. ${ }^{5,15}$ As described by Dick-

ABBREVIATIONS ADI = atlantodental interval; ALD1 = atlas lateral diameter; $\mathrm{ALD2}$ = axis lateral diameter; $\mathrm{CVJ}$ = craniovertebral junction; GCS = Glasgow Coma Scale; $\mathrm{mJOA}=$ modified Japanese Orthopaedic Association; TAL = transverse atlantal ligament.

SUBMITTED August 30, 2013. ACCEPTED September 23, 2015.

INCLUDE WHEN CITING Published online February 26, 2016; DOI: 10.3171/2015.9.SPINE13808. 


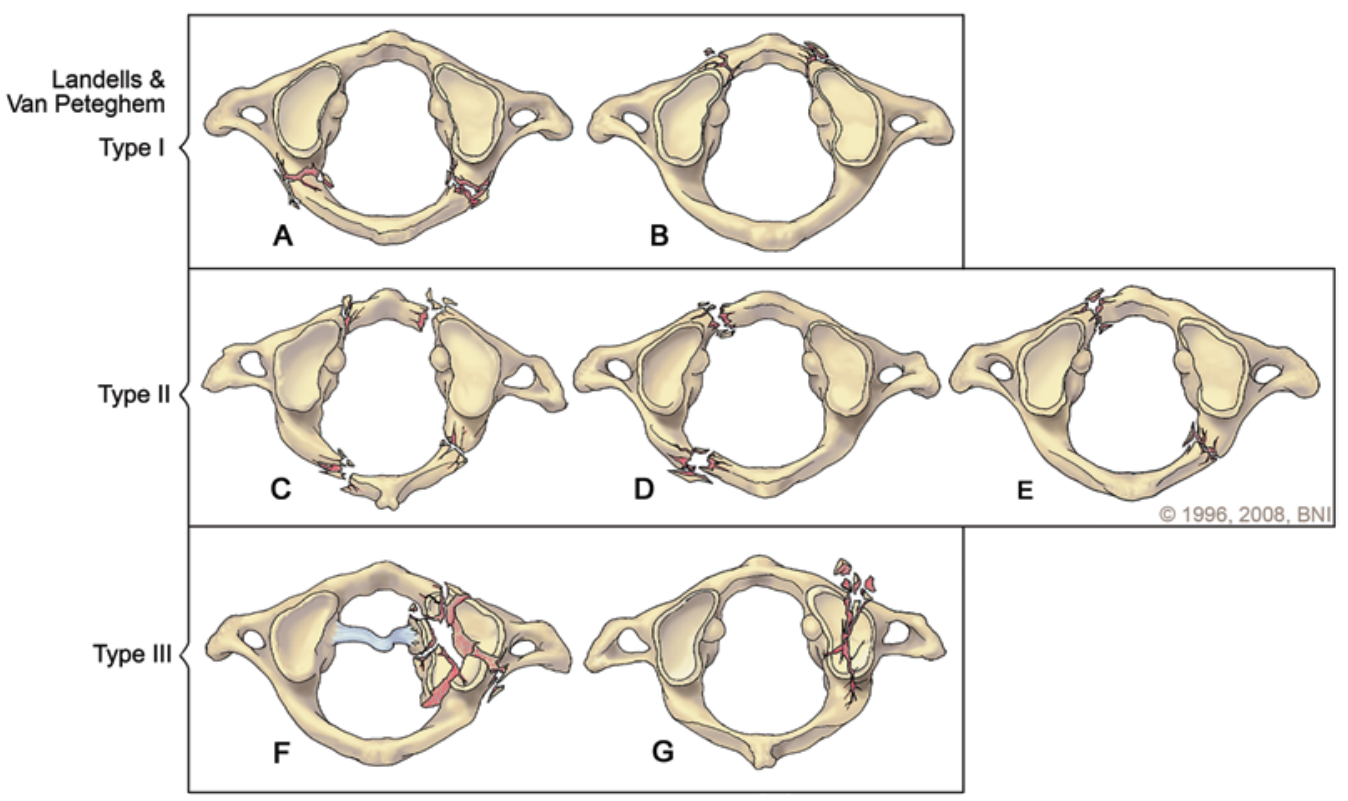

FIG. 1. Fracture classification systems of Jefferson ${ }^{8}$ and Landells and Van Peteghem. ${ }^{9}$ Jefferson Type I (A) and Type II (B) both correspond to Landells and van Peteghem Type I with isolated arch fractures. Classic Jefferson burst fractures (C) are Jefferson Type III and Landells and Van Peteghem Type II and include the fractures shown in $\mathbf{D}$ and $\mathbf{E}$. Lateral mass fractures (F and $\mathbf{G})$ are Jefferson Type IV and Landells and Van Peteghem Type III. From Dickman CA, Greene KA: Treatment of atlas fractures, in Menezes AH, Sonntag VKH (eds), Principles of Spinal Surgery, Vol 2. New York: McGraw-Hill, 1996, pp 855-869. Copyright Barrow Neurological Institute, Phoenix, Arizona. Published with permission.

man et al., all Type I TAL ruptures and most Type IIB ruptures require surgical stabilization to prevent future neurological injury (Fig. 2). ${ }^{6}$

In many tertiary health care centers, the integrity of the TAL is often assessed using MRI. However, many hos- pitals cannot provide MRI, and MRI is not possible for some patients. Debernardi et al. have questioned whether all patients with Type II odontoid fractures should undergo MRI. ${ }^{4}$ After finding that only one of 27 patients with Type II odontoid fractures demonstrated disruption
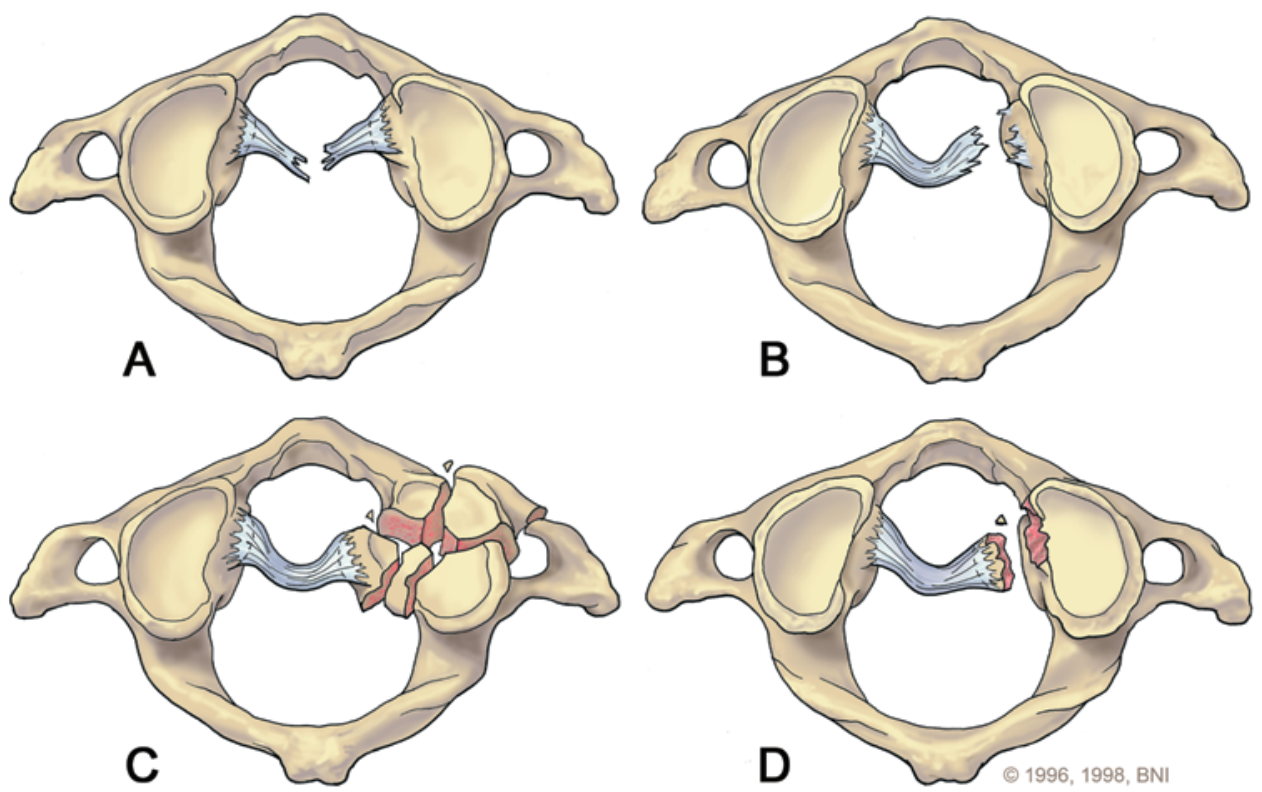

FIG. 2. Classification of injuries to the TAL: Type $1 A(A)$, Type IB (B), Type IIA (C), and Type IIB (D). The TAL, when disrupted at the midportion $(A)$ or at the insertion of the medial tubercle $(B)$, cannot heal when treated only with external immobilization. Bony avulsions $(C$ and $D$ ) have a good chance of healing when treated with external immobilization alone. From Dickman CA, Greene KA, Sonntag VKH: Injuries involving the transverse atlantal ligament: Classification and treatment guidelines based upon experience with 39 patients. Neurosurgery 38:44-50, 1996. Copyright Barrow Neurological Institute, Phoenix, Arizona. Published with permission. 
of TAL on MRI, this group argued that MRI should be performed only in select patients and in patients managed conservatively in need of strict surveillance. The objective of this study, which is the first of 2 phases, was to assess the utility of measurements made on CT scans intended to identify the integrity of the TAL in patients with traumatic injuries of the craniovertebral junction (CVJ), as an alternative to MRI.

\section{Methods}

This study was approved by the Institutional Review Board of St. Joseph's Hospital and Medical Center, Phoenix, Arizona.

Between December 2004 and September 2011, 125 patients (74 males and 51 females; mean age 52.8 years, range 2-94 years) with traumatic injuries involving the CVJ, defined as the osteoligamentous structures between and including the occipital condyles and second cervical vertebra, were evaluated at our institution. Patients were included for review in this study if they had undergone at least 1 cervical CT scanning study and 1 cervical MRI session that included soft-tissue sequences and if they had been evaluated by our spine service. Patients were excluded from the study if no demographic, comorbidity, followup, or surgical outcome data were available after thorough review of their medical records and computerized data. Patient data were assessed to identify mechanism of injury and medical conditions that would predispose patients to CVJ injuries. The clinical status of patients at presentation was recorded using the Glasgow Coma Scale (GCS) and the modified Japanese Orthopaedic Association (mJOA) scoring system. ${ }^{2}$

Each patient's type of injury was assessed both on cervical, 0.625-mm, axial-slice CT imaging (LightSpeed, GE Healthcare) and on 3-T MRI (Signa, GE Healthcare) that included soft-tissue sequences for study of the CVJosteoligamentous complex (Signa, GE Healthcare). A T2weighted MRI sequence was obtained within 72 hours of injury to identify acute traumatic edema of the soft tissue as a high-intensity signal. ${ }^{4}$ These images were analyzed by staff neuroradiologists, looking for injuries of the TAL, cruciate, apical, and atlantoaxial ligaments or of any other ligamentous structures of the CVJ. Patients with atlas fractures, odontoid process fractures, axis fractures without odontoid impairment, occipital condyle fracture, and TAL injuries were identified. Landells and Van Peteghem's ${ }^{9}$ system and Jefferson's ${ }^{8}$ system were used to classify atlantal fractures. Anderson and D'Alonzo's ${ }^{1}$ system was used to classify odontoid fractures, and Dickman's ${ }^{6}$ system was used to classify TAL injuries.

Clinical image management software (Dominator, DR Systems, Inc.) was used for quantitative anatomical analysis of the cases. We specifically focused on atlantal fractures, for which we measured the atlantodental interval (ADI, Fig. 3), atlas lateral diameter (ALD1), and axis lateral diameter (ALD2). Finally, we obtained the atlas lateral mass spread by subtracting ALD2 from ALD1 (ALD1 ALD2). The atlas/axis ratio was calculated as the coefficient between ALD1 and ALD2 expressed as a percentage $(A L D 1 / A L D 2 \times 100)$. Although this ratio is not described

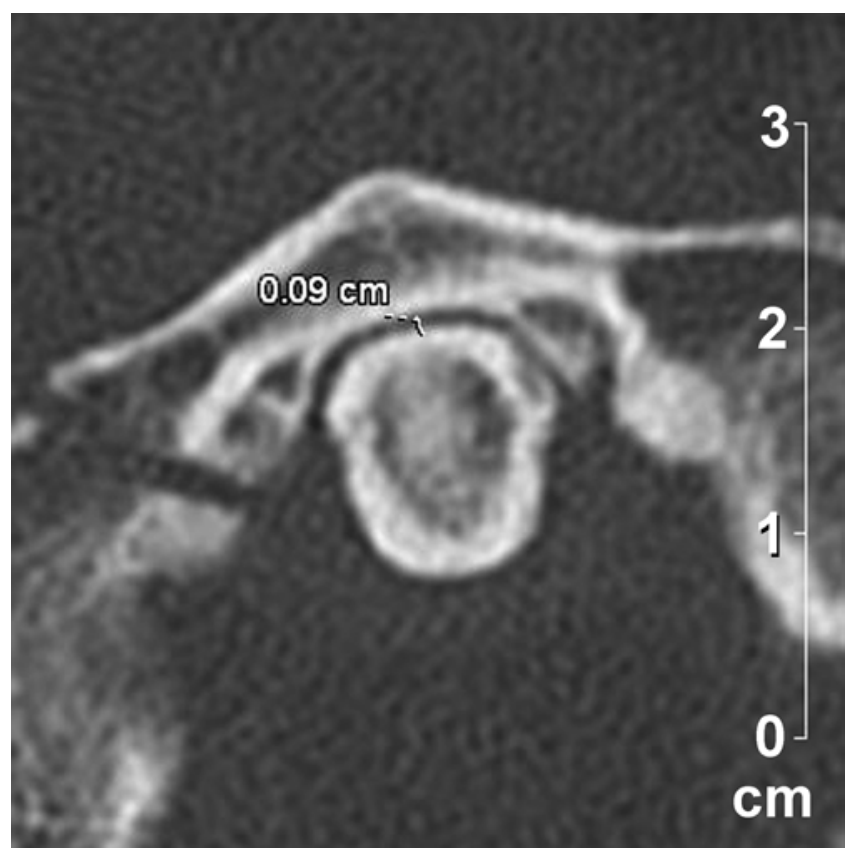

FIG. 3. Axial CT scan of the ADI measurement in a patient with an atlas fracture who was later diagnosed with a TAL injury after undergoing MRI.

in the literature, we evaluated it to explore whether assessing the integrity of the TAL using a proportion is more accurate than using a raw distance.

Statistical analysis was performed on a personal computer operating SigmaStat version 3.0 (SPSS). Independent t-tests were used to analyze differences in ADI, the atlas lateral mass spread, and the atlas/ax is ratio in patients with and without TAL injury. Significance was set at $p<0.05$.

\section{Results}

Of the 125 patients, $64(51.2 \%)$ were involved in a motor vehicle accident, $49(39.2 \%)$ suffered a ground-level fall, $6(4.8 \%)$ had a motorcycle or bicycle accident, 5 (4\%) were injured in a diving accident, and $1(0.8 \%)$ was injured during American football practice (Fig. 4). Twenty patients $(16 \%)$ had medical conditions specifically related to the craniocervical junction. Five patients (4\%) had rheumatoid arthritis, $11(8.8 \%)$ had bony metabolic diseases, 3 $(2.4 \%)$ had ankylosing spondylitis, and $1(0.8 \%)$ had Down syndrome.

At their initial clinical examination, 87 patients $(72.5 \%)$ had a GCS score of 15, $26(21.6 \%)$ had a GCS score between 14 and 9, and $7(5.8 \%)$ had a GCS score $\leq 9$. At presentation the mean mJOA score was 14.7 (range 1-18). Forty patients (32\%) had an atlas fracture, $59(47.2 \%)$ had an odontoid process fracture, $31(24.8 \%)$ had an axis fracture without odontoid impairment, and 4 (3.2\%) had an occipital condyle fracture (Fig. 5). Eleven patients $(8.8 \%)$ had a TAL injury.

In the 40 patients with an atlas fracture, 18 fractures (45\%) were Type I, 17 (42.5\%) were Type II, and 5 (12.5\%) were Type III, based on the Landells and Van Peteghem classification (Fig. 1). According to the Jefferson classification, 4 patients (10\%) had a Type I, 13 (32.5\%) had a 


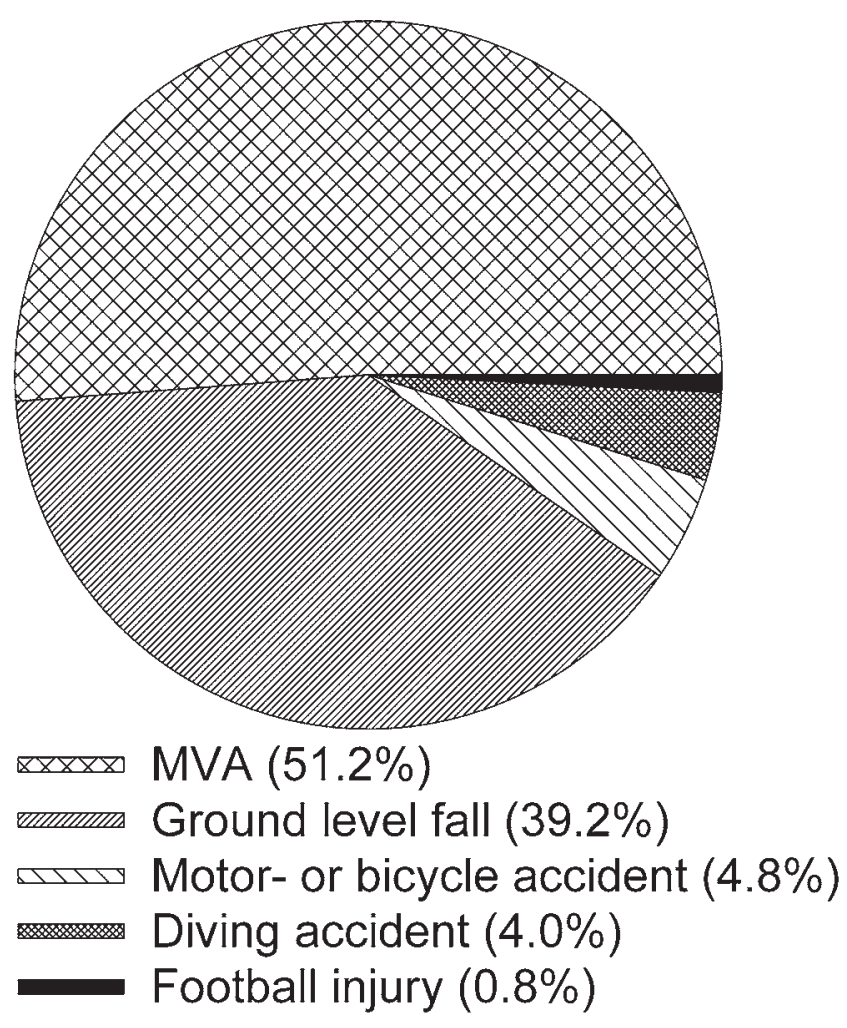

FIG. 4. Distribution of injury mechanisms in the 125 patients studied. MVA = motor vehicle accident.

Type II, 15 (37.5\%) had a Type III, and 8 (20\%) had a Type IV fracture. In 16 patients (40\%), the atlas fracture was combined with an odontoid fracture, all of which were Type II according to the Anderson and D'Alonzo classification. Only one of these combined fractures included a TAL injury. Two patients (5\%) had an atlas fracture combined with an axis body fracture. No atlas fractures were combined with an occipital condyle fracture. In 10 cases $(25 \%)$, the atlas fractures were combined with a TAL injury.

Of the 125 patients, 59 (47.2\%) had an odontoid process fracture. According to the Anderson and D'Alonzo classification, 2 (3.3\%) had a Type I fracture, $52(88.1 \%)$ had a Type II fracture, and $5(8.5 \%)$ had a Type III fracture (Fig. 1). In $16(27.1 \%)$ of 59 these cases, the odontoid fracture was combined with an atlas fracture. Only one $(1.7 \%)$ of the 59 patients with odontoid process fractures, representing $0.8 \%$ of the 125 cases analyzed, presented with a TAL injury.

Of the 125 patients, $31(24.8 \%)$ were diagnosed with an axis fracture without odontoid impairment. Three (9.7\%) of these cases involved a fracture of the axis body. Thirteen $(41.9 \%)$ had a unilateral posterior arch fracture. Fifteen $(48.4 \%)$ had a hangman's fracture. With respect to the TAL, $11(8.8 \%)$ of the 125 patients had an impairment of this ligament, 10 related to an atlas fracture and 1 related to an odontoid fracture. No preponderance was found for the mechanism of injury in this group.

On the basis of the imaging analysis of patients with an atlantal fracture, the mean atlantal lateral mass spread in the 10 patients with a TAL injury was $2.4 \mathrm{~mm}$ (range

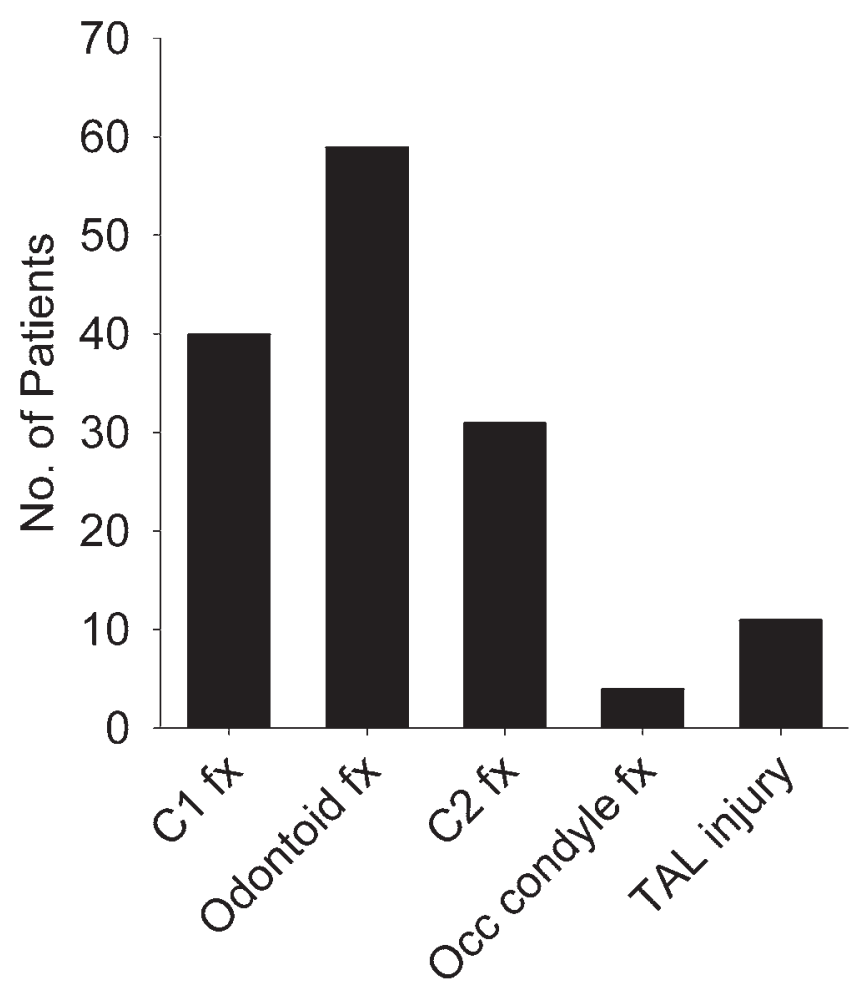

FIG. 5. Incidence of various types of CVJ injury in the patients studied. $F x=$ fracture; Occ = occipital.

0.6-8.7 mm). In the 30 patients with an atlantal fracture but no TAL injury, the mean lateral mass spread was 0.7 $\mathrm{mm}$. The difference was not significant $(\mathrm{p}=0.15$, Table 1$)$. The rule of Spence (lateral mass spread $\geq 7 \mathrm{~mm}$ ) did not apply to the 10 (90.9\%) patients with an atlas fracture and a TAL injury $(n=11)$. There was no significant difference $(\mathrm{p}=0.16$, Table 1) in the atlas/axis ratios of patients with (4.8\%) and without (1.5\%) TAL injury.

The mean average ADI in the 10 patients with atlas fractures and a TAL injury was $1.8 \mathrm{~mm}$ (range 0.9-3.9 $\mathrm{mm})$. The mean ADI in the 21 patients with an atlas fracture but no TAL injury was $1.3 \mathrm{~mm}$ (range $0-3.5 \mathrm{~mm}$ ). The difference was not significant $(\mathrm{p}=0.08$, Table 1$)$. Nine patients $(81.8 \%)$ with an atlas fracture and a TAL injury (n $=11$ ) had an ADI smaller than $3 \mathrm{~mm}$.

Seventy-two patients (57.6\%) underwent surgical treatment while $53(42.4 \%)$ were treated conservatively. In the surgical treatment group, 11 patients $(15.3 \%)$ underwent odontoid screw fixation, $24(33.3 \%)$ underwent posterior C1-2 fixation, 14 (19.4\%) underwent fusion extending to $\mathrm{C} 1$, and 23 (31.9\%) underwent occipitocervical fixation. In the conservative treatment group of 53 patients, $69.8 \%$ (n $=37)$ wore a collar and $30.2 \%(n=16)$ wore a halo vest.

\section{TABLE 1. Summary of measurements and $p$ values}

\begin{tabular}{lllc}
\hline \multicolumn{1}{c}{ Measurement } & TAL Injury & No TAL Injury & p Value \\
\hline $\begin{array}{l}\text { Mean C-1 lat mass spread } \\
\text { in mm (range) }\end{array}$ & $0.7(0.3-9.4)$ & $2.4(0.6-8.7)$ & 0.15 \\
\hline Atlas/axis ratio & $4.8 \%$ & $1.5 \%$ & 0.16 \\
\hline Mean ADI in mm (range) & $1.8(0.9-3.9)$ & $1.3(0-3.5)$ & 0.08 \\
\hline
\end{tabular}


The mean follow-up was 13.87 months (range 1-66 months). At their last follow-up visit, patients were clinically reevaluated with the mJOA score. The mean mJOA recovery rate was $75.2 \%$.

\section{Discussion}

Ever since Spence et al. published their study in $1970,{ }^{19}$ the measurement of the lateral spreading of the atlantal lateral masses with respect to the lateral limits of C-2 on a transoral radiography has been the standard for inferring impairment of the TAL after trauma. In 1970, Spence et al. study defined a distance of $\geq 7 \mathrm{~mm}$ as highly suspicious of a TAL injury (rule of Spence), with subsequent need for surgical stabilization. More recent studies, however, have found that a distance $\geq 7 \mathrm{~mm}$ is not an accurate method of diagnosing TAL impairment. By this criterion, approximately $61 \%$ of TAL injuries are missed. ${ }^{6,14}$

Another measurement widely used to assess TAL integrity, the ADI, is the distance between the anterior arch of $\mathrm{C}-1$ and the odontoid process, as measured on lateral cervical radiographs. Oda et al. proposed the $3-\mathrm{mm}$ limit for a normal ADI on a lateral flexion cervical radiographs. ${ }^{13}$ Using this criterion on lateral flexion-extension radiographs, Dickman et al. showed that about $25 \%$ of patients with an impairment of TAL are considered normal. ${ }^{6}$ Due to the lack of sensitivity of this option, and because its imaging definition is not the best, we excluded this option. Sayama et al. suggested that MRI is not required to screen for a TAL injury in the presence of Type II and shallow Type III odontoid fractures, ${ }^{17}$ but they defined a possible TAL injury as an ADI greater than $3 \mathrm{~mm}$.

In our study, the mean ADI for a TAL injury was 1.8 $\mathrm{mm}$ (range $0.9-3.9 \mathrm{~mm})$. Of 11 patients, $9(82 \%)$ had a TAL injury on MRI and an ADI less than $3 \mathrm{~mm}$. Furthermore, the mean ADI in patients with an atlas fracture without a TAL injury was $1.3 \mathrm{~mm}$, and there was no significant difference in the ADI with or without a TAL injury. Only one patient with a TAL injury had an odontoid Type II fracture. The ADI in this case was $1.2 \mathrm{~mm}$, and there was no overhang of the lateral masses of axis on the atlas. Thus, if we had used ADI alone or the rule of Spence rather than MRI to identify a TAL injury, we would have managed these patients inappropriately.

Our findings may differ from those of previous series $^{6,13,19}$ that based their analyses on radiographs. These series did not consider the magnification effect of this imaging technique, which may be a source of error in such measurements. ${ }^{12}$ Basing measurements on CT improves accuracy with an error rate of less than $5 \% .^{16,20}$

Although centers cannot rely only on radiography because of inaccuracies, they also cannot rely only on MRI. However, compared with MRI, CT is a rapidly obtained test, is more accessible worldwide, ${ }^{21}$ and is more cost-effective during the initial evaluation of a trauma patient. ${ }^{3}$ Our analysis shows that both an ADI greater than $3 \mathrm{~mm}$ and the rule of Spence lacked sensitivity: $90 \%$ of our patients with a TAL injury would have been misdiagnosed as not having an injury if we had relied solely on the rule of Spence. If we had used the diagnostic criterion of an ADI greater than $3 \mathrm{~mm}, 82 \%$ of our patients with a TAL injury would have been misdiagnosed.

\section{Conclusions}

To our knowledge, this is the first study that has attempted to assess the applicability of the current measurement criterion for the diagnosis of a TAL injury using CT. Both the rule of Spence and ADI lacked sensitivity for predicting a TAL injury. Further studies are needed to define a criterion using CT that would allow physicians without access to MRI to diagnose TAL injuries. In the second phase of this study, we will propose such a criterion.

\section{References}

1. Anderson LD, D'Alonzo RT: Fractures of the odontoid process of the axis. J Bone Joint Surg Am 56:1663-1674, 1974

2. Benzel EC, Lancon J, Kesterson L, Hadden T: Cervical laminectomy and dentate ligament section for cervical spondylotic myelopathy. J Spinal Disord 4:286-295, 1991

3. Berne JD, Velmahos GC, El-Tawil Q, Demetriades D, Asensio JA, Murray JA, et al: Value of complete cervical helical computed tomographic scanning in identifying cervical spine injury in the unevaluable blunt trauma patient with multiple injuries: a prospective study. J Trauma 47:896-903, 1999

4. Debernardi A, D’Aliberti G, Talamonti G, Villa F, Piparo M, Cenzato M: Traumatic (type II) odontoid fracture with transverse atlantal ligament injury: a controversial event. World Neurosurg 79:779-783, 2013

5. Debernardi A, D’Aliberti G, Talamonti G, Villa F, Piparo M, Collice M: The craniovertebral junction area and the role of the ligaments and membranes. Neurosurgery 68:291-301, 2011

6. Dickman CA, Greene KA, Sonntag VK: Injuries involving the transverse atlantal ligament: classification and treatment guidelines based upon experience with 39 injuries.

Neurosurgery 38:44-50, 1996

7. Hadley MN, Dickman CA, Browner CM, Sonntag VK: Acute traumatic atlas fractures: management and long term outcome. Neurosurgery 23:31-35, 1988

8. Jefferson G: Fractures of the atlas vertebra: report of four cases and a review of those previously recorded. Br J Surg 7:407-422, 1920

9. Landells CD, Van Peteghem PK: Fractures of the atlas: classification, treatment and morbidity. Spine (Phila Pa 1976) 13:450-452, 1988

10. Levine AM, Edwards CC: Fractures of the atlas. J Bone Joint Surg Am 73:680-691, 1991

11. Lowery DW, Wald MM, Browne BJ, Tigges S, Hoffman JR, Mower WR: Epidemiology of cervical spine injury victims. Ann Emerg Med 38:12-16, 2001

12. Matsunaga S, Kabayama S, Yamamoto T, Yone K, Sakou T, Nakanishi K: Strain on intervertebral discs after anterior cervical decompression and fusion. Spine (Phila Pa 1976) 24:670-675, 1999

13. Oda T, Panjabi MM, Crisco JJ III, Oxland TR, Katz L, Nolte LP: Experimental study of atlas injuries. II. Relevance to clinical diagnosis and treatment. Spine (Phila Pa 1976) 16 (10 Suppl):S466-S473, 1991

14. Panjabi MM, Oda T, Crisco JJ III, Oxland TR, Katz L, Nolte LP: Experimental study of atlas injuries. I. Biomechanical analysis of their mechanisms and fracture patterns. Spine (Phila Pa 1976) 16 (10 Suppl):S460-S465, 1991

15. Panjabi MM, Oxland TR, Parks EH: Quantitative anatomy of cervical spine ligaments. Part I. Upper cervical spine. J Spinal Disord 4:270-276, 1991

16. Prevrhal S, Engelke K, Kalender WA: Accuracy limits for the determination of cortical width and density: the influence 
of object size and CT imaging parameters. Phys Med Biol 44:751-764, 1999

17. Sayama CM, Fassett DR, Apfelbaum RI: The utility of MRI in the evaluation of odontoid fractures. J Spinal Disord Tech 21:524-526, 2008

18. Sherk HH, Nicholson JT: Fractures of the atlas. J Bone Joint Surg Am 52:1017-1024, 1970

19. Spence KF Jr, Decker S, Sell KW: Bursting atlantal fracture associated with rupture of the transverse ligament. J Bone Joint Surg Am 52:543-549, 1970

20. Waitzman AA, Posnick JC, Armstrong DC, Pron GE: Craniofacial skeletal measurements based on computed tomography: Part I. Accuracy and reproducibility. Cleft Palate Craniofac J 29:112-117, 1992

21. World Health Organization, Department of Essential Health Technologies: Baseline Country Survey on Medical Systems. Geneva: WHO Press, 2010

\section{Disclosures}

The authors report no conflict of interest concerning the materials or methods used in this study or the findings specified in this paper.

\section{Author Contributions}

Conception and design: Theodore, Perez-Orribo, Kalb, Hsu, Crawford. Acquisition of data: Perez-Orribo, Snyder, Kalb, Malhotra. Analysis and interpretation of data: Perez-Orribo, Newcomb, Crawford. Drafting the article: Snyder, Kalb, Malhotra. Critically revising the article: Theodore, Newcomb, Crawford. Reviewed submitted version of manuscript: Perez-Orribo, Elhadi, Crawford. Statistical analysis: Perez-Orribo, Newcomb, Crawford. Administrative/technical/material support: Elhadi. Study supervision: Theodore, Crawford.

\section{Supplemental Information}

Companion Papers

Perez-Orribo L, Kalb S, Snyder LA, Hsu F, Malhotra D, Lefevre $\mathrm{RD}$, et al: Comparison of CT versus MRI measurements of transverse atlantal ligament integrity in craniovertebral junction injuries. Part 2: A new CT-based alternative for assessing transverse ligament integrity. DOI: 10.3171/2015.9.SPINE13807.

\section{Correspondence}

Nicholas Theodore, c/o Neuroscience Publications, Barrow Neurological Institute, St. Joseph's Hospital and Medical Center, 350 W. Thomas Rd., Phoenix, AZ 85013.email: neuropub@ dignityhealth.org. 